\title{
Differences in the Histopathology and Cytokine Expression Pattern between Chronological Aging and Photoaging of Hairless Mice Skin
}

\author{
Masaaki Sakura1,2,3, Yoichi Chiba2,4*, Emi Kamiya1, Ayako Furukawa5, Noriko Kawamura², \\ Masanao Niwa1, Minoru Takeuchi' ${ }^{3}$, Yasushi Enokido' ${ }^{2}$, Masanori Hosokawa ${ }^{2}$ \\ ${ }^{1}$ Fundamental Research Laboratory, General Research \& Development Institute, Hoyu Co., Ltd., Nagakute, \\ Japan \\ ${ }^{2}$ Department of Pathology, Institute for Developmental Research, Aichi Human Service Center, Kasugai, Japan \\ ${ }^{3}$ Faculty of Life Science, Kyoto Sangyo University, Kyoto, Japan \\ ${ }^{4}$ Department of Pathology and Host Defense, Faculty of Medicine, Kagawa University, Miki, Japan \\ ${ }^{5}$ Faculty of Pharmaceutical Sciences, Suzuka University of Medical Science, Suzuka, Japan \\ Email: ${ }^{*}$ ychiba@med.kagawa-u.ac.jp
}

Received 23 May 2014; revised 20 June 2014; accepted 15 July 2014

Copyright (C) 2014 by authors and Scientific Research Publishing Inc.

This work is licensed under the Creative Commons Attribution International License (CC BY).

http://creativecommons.org/licenses/by/4.0/

(c) (i) 0 pen Access

\section{Abstract}

Skin photoaging is a complex, multifactorial process resulting in functional and structural changes of the skin, and different phenotypes from chronological skin aging are well-recognized. Ultraviolet (UV)-irradiated hairless mice have been used as a skin photoaging animal model. However, differences in morphology and gene expression patterns between UV-induced and chronological skin changes in this mouse model have not been fully elucidated. Here we investigated differences in histopathology and cytokine expression between UV-irradiated and non-irradiated aged hairless mice to clarify the factor(s) that differentiate photoaging from chronological skin aging phenotypes. Eight-week-old HR-1 hairless mice were divided into UV-irradiated (UV-irradiated mice) and non-irradiated (control mice) groups. Irradiation was performed three times per week for 10 weeks. In addition, 30-week-old HR-1 hairless mice were reared until 70 weeks of age without UV irradiation (aged mice). Histopathologies revealed that the flattening of dermal-epidermal junctions and epidermal thickening were observed only in UV-irradiated mice. Decreases in fine elastic fibers just beneath the epidermis, the thickening of elastic fibers in the reticular dermis, and the accumulation of glycosaminoglycans were more prominent in UV-irradiated mice as compared to non-irradiated aged mice. Quantitative PCR analyses revealed that UV-irradiated mice showed

\footnotetext{
${ }^{*}$ Corresponding author.
} 
an increase in the expression of IFN- $\gamma$. In contrast, aged mice exhibited proportional up-regulation of both pro-inflammatory and anti-inflammatory cytokines. The IFN- $\gamma / \mathrm{IL}-4$ ratio, an indicator for the balance of pro-inflammatory and anti-inflammatory cytokines, was significantly higher in UVirradiated mice as compared to control and non-irradiated aged mice. An elevated IFN- $\gamma / \mathrm{IL}-4$ ratio was also observed in aged senescence-accelerated mouse-prone 1 (SAMP1) mice, a spontaneous skin photoaging model we recently reported. Thus, an imbalance between pro-inflammatory and anti-inflammatory cytokines might be a key factor to differentiate photoaged skin from chronologically-aged skin.

\title{
Keywords
}

\author{
Photoaged Skin, Chronologically-Aged Skin, Pro-Inflammatory Cytokines, Anti-Inflammatory \\ Cytokines, Hairless Mice
}

\section{Introduction}

Cutaneous aging is a complex biological phenomenon affecting various constituents of the skin. There are two independent, clinically and biologically distinct, processes affecting the skin [1]. The first is the intrinsic or chronological aging process, which is characterized by slow and irreversible tissue degeneration and affects the skin as well as the whole body. The second process is the extrinsic aging or photoaging, which is provoked by chronic exposure to sunlight, especially ultraviolet (UV) light [2] [3]. Photoaged skin in the elderly, which is typically observed in sun-exposed areas such as the face, shows a variety of clinical manifestations including coarseness, wrinkling, a sallow discoloration, telangiectasia, and irregular pigmentation [4]. Photoaging is histologically characterized by the progressive fragmentary destruction of the elastic fiber network; i.e., the replacement of dermal elastic fibers with dystrophic elastotic materials [5]. This is the most prominent histologic feature of photoaged skin, which is referred to as solar elastosis [6]. Other histological changes characterizing photoaged skin include an increase in the deposition of glycosaminoglycans (GAGs) [7] [8] and the formation of the Grenz zone [2]. In contrast, the skin at photo-protected sites in the elderly, such as the abdomen, exhibits increased laxity and fold accentuation, but clearly does not develop the leathery, sagging appearance of the actinically damaged integument [9]. The histological differences between the two states are mainly attributed to differential changes in the dermal extracellular matrix and epidermal hyperplasia [4] [9] [10].

Reactive oxygen species (ROS), generated by UVA and/or UVB irradiation, have been hypothesized to be an important factor for the pathogenesis of photoaged skin. UV-induced ROS can exert a multitude of effects such as lipid peroxidation, the activation of transcription factors and the generation of DNA strand breaks [3]. Moreover, UV radiation stimulates and activates various cells to produce and release pro-inflammatory cytokines and matrix metalloproteinases (MMPs), which play an important role in the process of photoaging [11]. However, these factors also contribute to chronological skin aging [12]-[14], and what factor(s) differentiate between chronological aging and photoaging phenotypes in the skin still remain to be elucidated.

It is important to study how the intrinsic aging process contributes to the pathogenesis of photoaging, since human photoaging is considered to be the superposition of solar damage on the normal aging process [1]. Studying the pathogenesis of photoaged skin in humans is difficult because of the decades needed for the evolution of this process, and the inability to assess the total exposure of an individual [15]. Therefore, UV-irradiated hairless mice are widely used as an animal model for skin photoaging [16]. In this model, UV irradiation is generally started at 6 to 8 weeks of age, and 10 to 22 weeks of irradiation is sufficient to produce human photoaged skin-like lesions [17] [18]. Thus, photoaged skin-like lesions can be reproduced in hairless mice without an intrinsic senescence process. Such a situation may be the reason why there have been few studies on skin phenotypes of chronological aging in hairless mice so far [19] [20].

We have recently reported a spontaneous animal model for photoaging, probably caused by an exaggerated intrinsic mechanism [21]. Accelerated senescence-prone (SAMP) mice show an accelerated senescence process, shorter lifespan, higher oxidative status, and an earlier onset and more rapid progression of age-associated pathological phenotypes as compared to accelerated senescence-resistant (SAMR) mice, a closely related control 
strain which shows a normal aging process [22]-[24]. SAMP1 mice, a strain of the SAMP mice, exhibited histopathological and gene expression changes similar to those in human photoaged skin with advancing age, even in the absence of UV irradiation. The changes included an increase in elastic fibers and GAGs, an up-regulation of several pro-inflammatory cytokines and MMPs, and an increase in lipid peroxide in the dorsal skin. In contrast, SAMR1 mice did not exhibit such skin changes at an older age [21]. On the basis of these findings, we have proposed that aggravated intrinsic mechanisms, i.e., higher oxidative status, might induce photoaging-like phenotypes in SAMP1 mice.

In the present study, we investigated differences in histopathological findings and cytokine expression of nonirradiated skin at an advanced age (70 weeks of age), and UV-irradiated and non-irradiated skin at a young age (18 weeks of age) in hairless mice. We found different histological and cytokine expression changes in the skin between chronologically-aged and UV-irradiated hairless mice, and an imbalance in the expression between proinflammatory and anti-inflammatory cytokines might be a factor that differentiates photoaging skin phenotypes from chronological aging phenotypes.

\section{Materials and Methods}

\subsection{Animals}

Male albino hairless HOS: HR-1 hairless mice (6 weeks or 30 weeks of age) were purchased from Hoshino Laboratory Animals Co., Ltd. (Saitama, Japan). Mice were reared under conventional conditions, housed at $23^{\circ} \mathrm{C} \pm$ $2^{\circ} \mathrm{C}$, and were allowed free access to food (CE2, Nihon CLEA, Tokyo, Japan) and tap water. The light-dark cycle was set at 12 hours (lights were on at 07:00). Six-week-old male hairless mice were acclimated for 2 weeks in our animal facility, after which they were subjected to UV irradiation. They were divided into UV-irradiated $(n=4)$ and non-irradiated (control) $(n=4)$ groups. Thirty-week-old male hairless mice were reared until 70 weeks of age without UV irradiation (aged mice) $(n=5)$. We checked all of the mice pathologically after sampling of skin specimens, and excluded samples from mice with inflammation-associated pathologies (pneumonia and other inflammatory changes) and/or tumors from all subsequent analyses.

We took special care to minimize the number of animals used and their suffering. All animals were handled in accordance with the Guide for the Care and Use of Laboratory Animal of the Institute for Developmental Research, Aichi Human Service Center.

\subsection{UVB Irradiation}

UV irradiation was performed according to a method described by Schwartz et al. [25], with some modifications. Briefly, a Handheld UV Lamp UVM-57 (UVP Inc., CA, USA) was used as a source of UVB. The wavelength of the irradiated UV was $280-315 \mathrm{~nm}$. A mouse was placed in a cage $(12 \times 9 \times 3 \mathrm{~cm})$ and positioned at the center of the UVB source. The cage was covered by thin wire netting such that the mice were evenly exposed to the UV. The UV intensity was measured using a UV radiometer YK-34UV (Lutron Electronic Co., Taipei, Taiwan) with spectral sensitivity within the range of 290 - $390 \mathrm{~nm}$. The dorsal skin of the mice was irradiated three times per week for 10 weeks. The total irradiated dose was about $4 \mathrm{~J} / \mathrm{cm}^{2}$. Skin tissues were removed two days after the completion of the UV irradiation.

\subsection{Histological Examinations}

Each mouse was sacrificed by cervical dislocation, and the dorsal skin was rapidly removed, immersed in $10 \%$ neutral buffered formalin ( $\mathrm{pH}$ 7.4) for 7 days, and then embedded in paraffin. Twenty-micron-thick sections were cut with a sliding microtome, and hematoxylin-eosin (H\&E), resorcin-fuchsin and alcian blue stainings were performed according to standard procedures.

The thickness of the epidermis was evaluated using sections stained with H\&E. Photomicrographs of continuous, non-overlapping visual fields $(736 \times 533 \mu \mathrm{m})$ were obtained to cover the entire epidermis of the specimen using a digital microscope (VHX-200, Keyence Corporation, Osaka, Japan). The thickness of the epidermis was measured at 10 locations set at an interval of $70 \mu \mathrm{m}$ apart, and the average thickness was calculated.

\subsection{RNA Extraction and Real-Time Quantitative PCR}

Dorsal skin was dissected from each mouse, and washed in ice-cold phosphate-buffered saline (PBS). Total 
RNA was isolated using an ISOGEN kit (NIPPON GENE CO., LTD., Tokyo, Japan) according to the manufacturer's instructions. RNA yields and purities were determined by spectrophotometric absorption analyses at 260/280 nm. The cDNA was synthesized from total RNA using the Super Script ${ }^{\mathrm{TM}}$ III First-Strand Synthesis System for RT-PCR (Invitrogen, Carlsbad, CA, USA) according to the manufacturer's instructions.

Gene expression was analyzed by a real time PCR system (ABI Stepone-Plus, Applied Biosystems, Foster City, CA, USA) with each cDNA sample, specific Taqman primers/probes and a Taqman Universal PCR Master Mix (Applied Biosystems). The following probes were used (identified by Applied Biosystems assay identification number): IL-1 beta (IL-1 $\beta$ ), Mm00434228_m1; TNF-alpha (TNF- $\alpha$ ), Mm00443258_m1; IL-6,

Mm00446190_m1; IFN-gamma (IFN- $\gamma$ ), Mm00801778_m1; TGF-beta1 (TGF- $\beta 1$ ), Mm00441724_m1; iNOS, Mm00440485_m1; IL-4, Mm00445260_m1; IL-10, Mm00439616_m1 and 18S rRNA, Hs99999901_s1. 18S rRNA was used as an internal control. The expression of these mRNA species was analyzed using the same sets as for the total RNA samples. Reaction mixtures were subjected to the following amplification scheme: 1 cycle at $50^{\circ} \mathrm{C}$ for 2 min (AmpErase uracil-N-glycosylasedeactivation) and 1 cycle at $95^{\circ} \mathrm{C}$ for $10 \mathrm{~min}$ (AmpliTaq Gold activation), followed by 40 cycles at $95^{\circ} \mathrm{C}$ for $15 \mathrm{~s} \mathrm{(denaturation)} \mathrm{and} 60^{\circ} \mathrm{C}$ for $1 \mathrm{~min}$ (annealing and extension).

\subsection{Statistical Analyses}

Data were expressed as means \pm SD. A one-way analysis of variance (ANOVA) followed by Tukey's procedure were performed to determine differences in epidermal thickness and the expression of mRNA among control, aged and UV-irradiated groups of hairless mice. Differences were considered to be statistically significant when $p<0.05$.

\section{Results}

\subsection{Histological Analyses}

In H\&E-stained sections, spike-like downgrowths in the area of the dermal-epidermal junction (DEJ) were evident in both control and aged mice (Figure 1(a), Figure 1(d)). In contrast, UV-irradiated mice showed an increase in the area of flattened DEJ (Figure 1(g)). UV-irradiated mice, but not aged mice, showed marked thickening of the epidermis (Figure 1(a), Figure 1(d), Figure 1(g)). A one-way ANOVA showed a significant effect for aging type $(\mathrm{F}(2,10)=50.6086, p<0.0001)$ in the epidermal thickness. In UV-irradiated mice, the epidermis was $38.80 \pm 5.85 \mu \mathrm{m}$ thick, which was 2.3 -fold thicker than in control mice $(17.21 \pm 1.54 \mu \mathrm{m})$ and 2.4 -fold thicker than in aged mice $(16.38 \pm 2.42 \mu \mathrm{m})$. In contrast, Tukey's procedure revealed no significant differences exist between control and aged mice $(p=0.9386)$.

In resorcin-fuchsin-stained sections, fine elastic fibers just beneath the epidermis were fewer in aged mice (Figure 1(b), Figure 1(e), open arrowheads). The elastic fibers in the reticular dermis were thickened in aged mice as compared to control mice (Figure 1(e), thin arrow). In the UV-irradiated mice, the above mentioned changes were more pronounced as compared to control mice (Figure 1(h), open arrowhead and thin arrow).

In alcian blue-stained sections, a slight accumulation of alcian blue-positive GAGs was observed just beneath the epidermis of aged mice (Figure 1(c), Figure 1(f), closed arrowheads). The UV-irradiated mice showed a more prominent accumulation of GAGs just beneath the epidermis (Figure 1(i), closed arrowheads).

\subsection{Gene Expression Analyses by Real-Time RCR}

A one-way ANOVA revealed no significant effect for aging type (control, UV-irradiated and chronologicallyaged) in the expression of IL- $1 \beta$ mRNA $(\mathrm{F}(2,10)=1.0554, p=0.3838)$ or IL-6 mRNA $(\mathrm{F}(2,10)=2.8796, p=$ 0.1029) (Figure 2(a), Figure 2(c)).

In the expression of TNF- $\alpha$ mRNA, a one-way ANOVA showed a significant effect for the aging type $(\mathrm{F}(2,10)$ $=8.3231, p=0.0074)$. TNF- $\alpha$ mRNA expression in aged mice was significantly greater than in control and UV-irradiated mice, whereas there was no significant difference between control and UV-irradiated mice (Figure 2(b)).

In the expression of IFN- $\gamma$ mRNA, a one-way ANOVA showed a significant effect for the aging type $(\mathrm{F}(2,10)$ $=12.0917, p=0.0021)$. Tukey's procedure revealed significantly greater IFN- $\gamma$ mRNA expression in UV-irradiated mice as compared to control (5.8-fold) and aged (2.0-fold) mice (Figure 2(d)). 


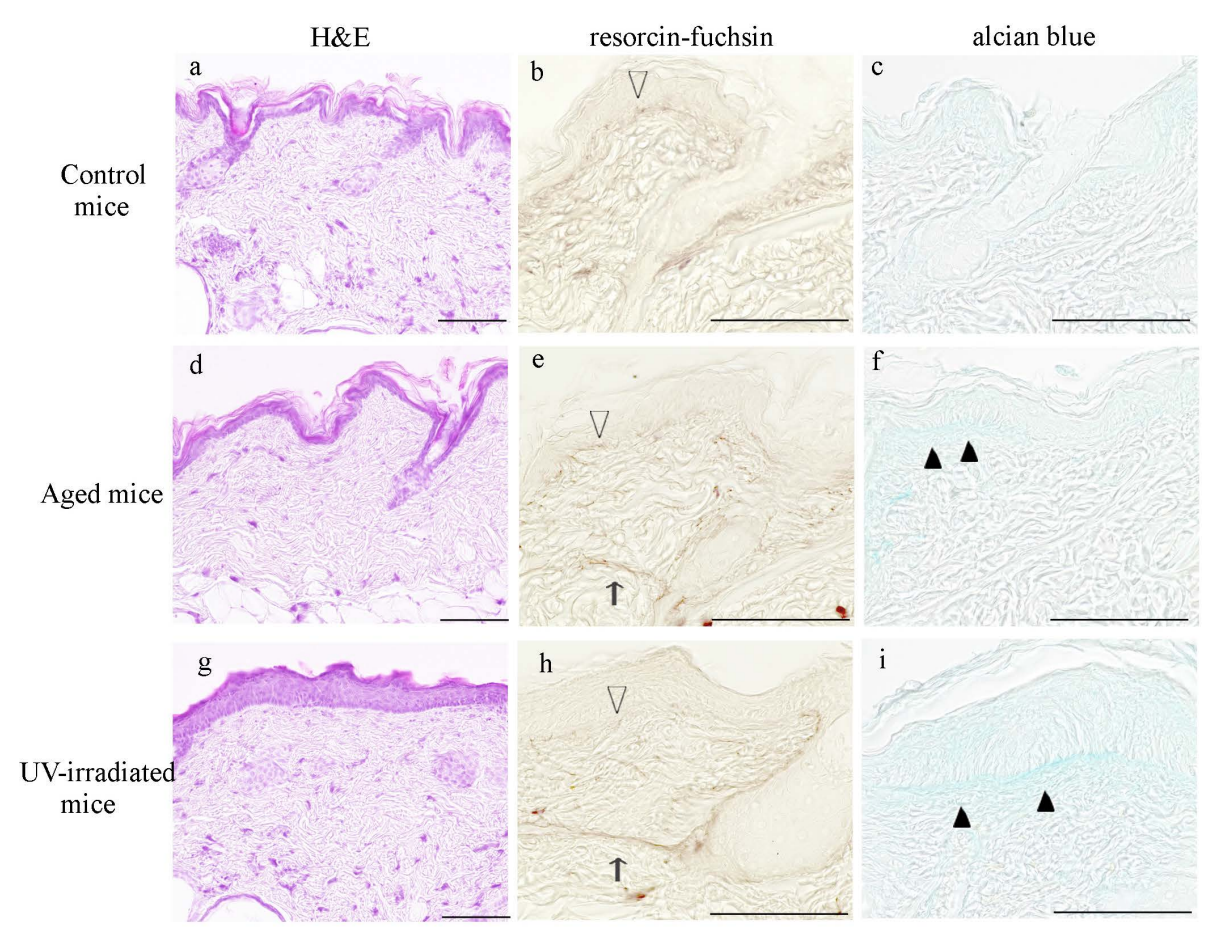

Figure 1. Histological changes in the dorsal skin of hairless mice. Representative photomicrographs of the dorsal skin from control (a)-(c), aged (d)-(f) and UV-irradiated (g)-(i) hairless mice. Formalin-fixed skin sections were stained with hematoxylin and eosin (a), (d), (g), resorcin-fuchsin (b), (e), (h) and alcian blue (c), (f), (i). The open arrowheads in (e) and (h) indicate decreased fine elastic fibers in the dermal-epidermal junction, and the thin arrows indicate thickened elastic fibers in the reticular dermis. The closed arrowheads in (f) and (i) indicate increased glycosaminoglycans. Photomicrographs were taken with a reduced condenser aperture. See the text for a detailed description. Scale bars: $100 \mu \mathrm{m}$.

In the expression of TGF- $\beta$ mRNA, a one-way ANOVA showed a significant effect for the aging type $(\mathrm{F}(2,10)$ $=29.3000, p=0.0001)$. TGF- $\beta$ mRNA levels in aged mice were significantly greater than those in control and UV-irradiated mice. No significant differences were detected between control and UV-irradiated mice (Figure 2(e)).

In the expression of iNOS mRNA, a one-way ANOVA showed a significant effect for the aging type $(\mathrm{F}(2,10)$ $=23.4744, p=0.0002)$. iNOS mRNA levels in aged mice were significantly greater than those in control and UV-irradiated mice. No significant differences were detected between control and UV-irradiated mice (Figure 2(f)).

In the expression of IL-4 mRNA, a one-way ANOVA showed a significant effect for the aging type $(\mathrm{F}(2,10)$ $=5.0001, p=0.0312$ ). IL-4 mRNA levels in aged mice were 3.3-fold higher than those in control mice. In contrast, no significant differences were detected between control and UV-irradiated mice (Figure 2(g)).

In regards to the expression of IL-10, a one-way ANOVA showed a significant effect for the aging type $(\mathrm{F}(2$, $10)=6.7659, p=0.0139$ ). IL-10 mRNA levels in aged mice were 3.4-fold greater than those in control mice. In contrast, no significant differences were detected between control and UV-irradiated mice (Figure 2(h)).

To evaluate the balance between pro-inflammatory and anti-inflammatory cytokines, we compared the IFN- $\gamma /$ IL-4 ratio among control, aged and UV-irradiated mice (Figure 2(i)). A one-way ANOVA showed a significant effect for the aging type $(F(2,10)=40.6563, p<0.0001)$. The IFN- $\gamma /$ IL-4 ratio was significantly greater in UVirradiated mice than in control and aged mice. In contrast, there was no significant difference in the IFN- $\gamma / \mathrm{IL}-4$ ratio between control and aged mice (Figure 2(i)).

\section{Discussion}

In the present study, we showed that aged (70-week-old) hairless mice exhibited minimal changes in their der- 

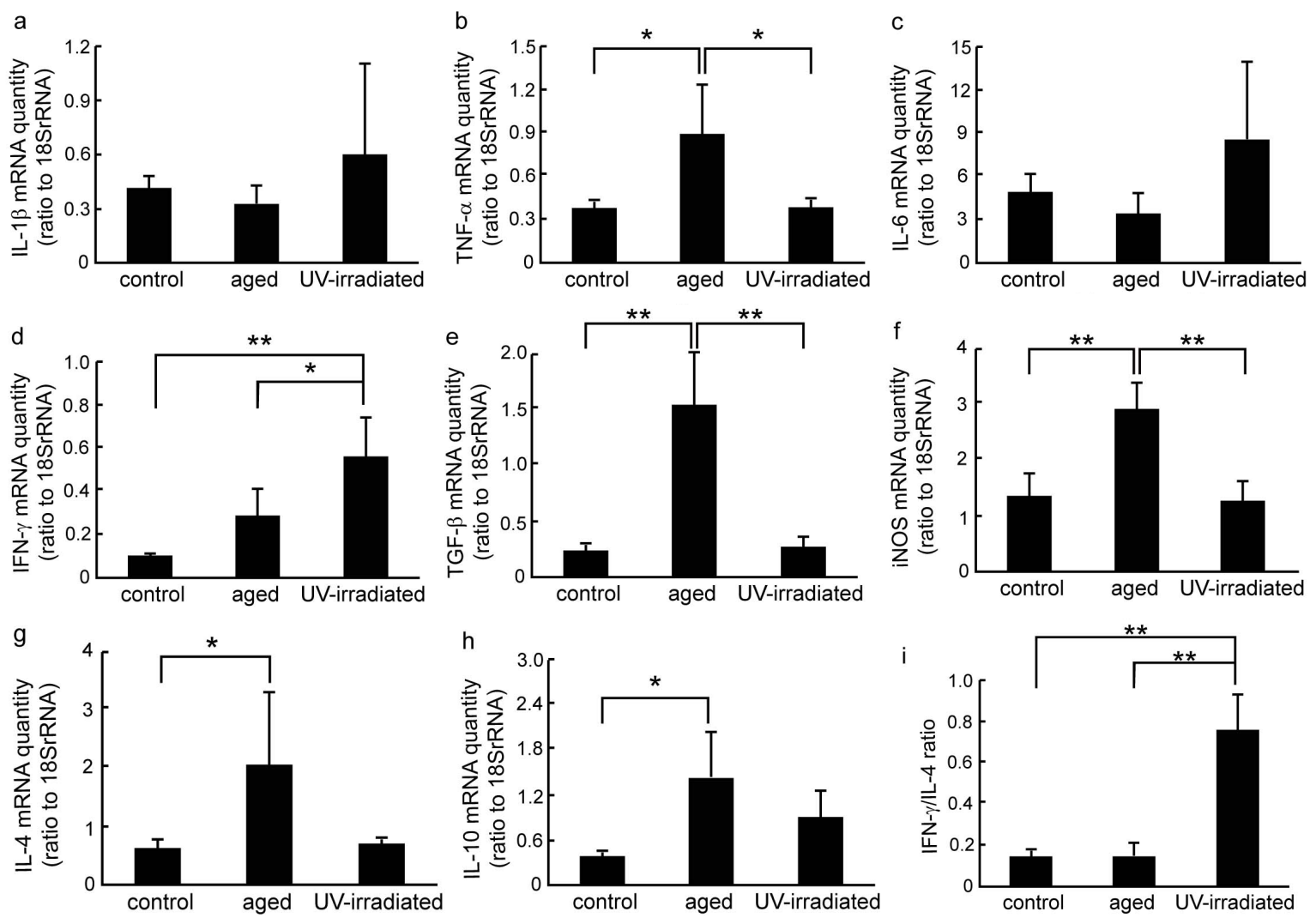

Figure 2. Changes in the expression of inflammation-related molecules in the skin from hairless mice. The expression of IL-1 $\beta$ (a), TNF- $\alpha$ (b), IL-6 (c), IFN- $\gamma$ (d), TGF- $\beta$ (e), iNOS (f), IL-4 (g) and IL-10 (h) mRNAs in the skin from control, aged and UV-irradiated hairless mice were analyzed by real-time PCR. The relative levels of mRNA were obtained by dividing the quantity of each mRNA by that of $18 \mathrm{~S}$ rRNA as the internal standard. (i) indicates the IFN- $\gamma / \mathrm{IL}-4$ ratio. All data are presented as means \pm SD. The number of mice used in this experiment ranged from 4 to 5 for each experimental group. $(*) p<0.05,(* *) p<0.01$.

mal elastic fibers and GAGs without epidermal thickening. These changes were similar to those in a previous report by Kligman et al. [19], and to the pathology of chronologically-aged skin in photo-protected areas in humans, except for the absence of flattening of DEJ [7]. In contrast, we were able to reproduce photoaging-like histological changes, such as alterations in dermal elastic fibers, the deposition of GAG and thickening of the epidermis [1] [2], in hairless mice by UV irradiation for 10 weeks. Thus, chronological factors may have little, if any, contribution to the pathogenesis of the photoaging-like phenotype in hairless mice, and UV irradiation seems to be a necessary and sufficient factor.

ROS, pro-inflammatory cytokines and MMPs are thought to be key factors for the pathogenesis of photoaging [3] [11]. On the other hand, these factors also contribute to the intrinsic aging process of the skin [12]-[14]. Accumulating evidence suggests that photoaging and chronological aging share some important molecular features, and photoaging can be regarded as the superposition of solar damage on the normal aging process [1] [14]. To investigate differentiating molecular factor(s) between photoaging and chronological aging, we focused on the pattern of cytokine expression in hairless mice models for these two aging phenotypes. We found that chronologically aged hairless mice showed an increase in the expression of both pro-inflammatory molecules, such as TNF- $\alpha$ and iNOS, and anti-inflammatory molecules, such IL-4 and IL-10. In contrast, UV-irradiated hairless mice showed a marked increase in IFN- $\gamma$ expression, but no significant increase in anti-inflammatory cytokines. A balanced production of pro-inflammatory and anti-inflammatory cytokines is important for an appropriate immune response [26]-[28], and an imbalance between pro-inflammatory and anti-inflammatory cytokines has been reported in psoriasis, a chronic inflammatory skin disease caused by autoimmune mechanisms [29]. To evaluate the balance between pro-inflammatory and anti-inflammatory cytokines in these two aging phenotypes, we calculated the IFN- $\gamma / \mathrm{IL}-4$ ratio [26] [30]. In chronologically-aged skin, the IFN- $\gamma / \mathrm{IL}-4$ ratio was similar to 
that in control mice, suggesting that the pro-inflammatory/anti-inflammatory balance is maintained in aged hairless mice. In contrast, UV-irradiated hairless mice showed a significant increase in their IFN- $/$ IL-4 ratio. Thus, although not all pro-inflammatory cytokines were increased in UV-irradiated mice, the imbalance between proinflammatory versus anti-inflammatory cytokines might be a differentiating factor between the two aging phenotypes in the skin.

To confirm the association between the skin photoaging phenotype and the shift to pro-inflammatory status, we evaluated the IFN- $\gamma /$ IL-4 ratio in SAMP1 mice, another skin photoaging model [21]. The IFN- $\gamma /$ IL-4 ratio of the skin from 70-week-old SAMP1 mice was markedly increased as compared to that of 12-week-old SAMP1 mouse skin (6.64 \pm 2.44 and $0.06 \pm 0.03$, respectively: $p=0.0038$, unpublished data). In contrast, the IFN- $\gamma / \mathrm{IL}-4$ ratios in 70-week-old and 12-week-old SAMR1 mice skin were $0.18 \pm 0.05$ and $0.14 \pm 0.05$, respectively ( $p=$ 0.275 , unpublished data). Thus, the imbalance between pro-inflammatory and anti-inflammatory cytokines seems to be a common feature of UV-irradiated hairless mice and old SAMP1 mice, which are both skin photoaging models.

\section{Conclusion}

In summary, chronologically-aged skin and photoaged skin in hairless mice exhibited different histological and gene expression changes, and an imbalance between pro-inflammatory and anti-inflammatory cytokines indicated by an elevated IFN- $\gamma / \mathrm{IL}-4$ ratio, which might be a key factor to differentiate these two phenotypes of skin aging. How the pro-inflammatory/anti-inflammatory imbalance affects the phenotypes of photoaged skin deserves further investigation. Our results add to the fundamental understanding of the regulatory mechanisms between photoaged skin and chronologically-aged skin in photo-protected skin.

\section{Acknowledgements}

We thank T Kitajima and T Hiraide for their technical assistances.

\section{References}

[1] Farage, M.A., Miller, K.W., Elsner, P. and Maibach, H.I. (2008) Intrinsic and Extrinsic Factors in Skin Ageing: A Review. International Journal of Cosmetic Science, 30, 87-95. http://dx.doi.org/10.1111/j.1468-2494.2007.00415.X

[2] Kligman, L.H. and Kligman, A.M. (1986) The Nature of Photoaging: Its Prevention and Repair. Photodermatology, 3, 215-227.

[3] Rabe, J.H., Mamelak, A.J., McElgunn, P.J., Morison, W.L. and Sauder, D.N. (2006) Photoaging: Mechanisms and Repair. Journal of the American Academy of Dermatology, 55, 1-19. http://dx.doi.org/10.1016/j.jaad.2005.05.010

[4] Gilchrest, B.A. (1989) Skin Aging and Photoaging: An Overview. Journal of the American Academy of Dermatology, 21, 610-613. http://dx.doi.org/10.1016/S0190-9622(89)70227-9

[5] Braverman, I.M. and Fonferko, E. (1982) Studies in Cutaneous Aging: I. The Elastic Fiber Network. The Journal of Investigative Dermatology, 78, 434-443. http://dx.doi.org/10.1111/1523-1747.ep12507866

[6] Lee, J.Y., Kim, Y.K., Seo, J.Y., et al. (2008) Loss of Elastic Fibers Causes Skin Wrinkles in Sun-Damaged Human Skin. Journal of Dermatological Science, 50, 99-107. http://dx.doi.org/10.1016/j.jdermsci.2007.11.010

[7] Mukherjee, S., Date, A., Patravale, V., Korting, H.C., Roeder, A. and Weindl, G. (2006) Retinoids in the Treatment of Skin Aging: An Overview of Clinical Efficacy and Safety. Clinical Interventions in Aging, 1, 327-348.

[8] Werth, B.B., Bashir, M., Chang, L. and Werth, V.P. (2011) Ultraviolet Irradiation Induces the Accumulation of Chondroitin Sulfate, but Not Other Glycosaminoglycans, in Human Skin. PLoS One, 6, e14830. http://dx.doi.org/10.1371/journal.pone.0014830

[9] El-Domyati, M., Attia, S., Saleh, F., et al. (2002) Intrinsic Aging vs. Photoaging: A Comparative Histopathological, Immunohistochemical, and Ultrastructural Study of Skin. Experimental Dermatology, 11, 398-405. http://dx.doi.org/10.1034/j.1600-0625.2002.110502.x

[10] Naylor, E.C., Watson, R.E. and Sherratt, M.J. (2011) Molecular Aspects of Skin Ageing. Maturitas, 69, $249-256$. http://dx.doi.org/10.1016/j.maturitas.2011.04.011

[11] Yaar, M. and Gilchrest, B.A. (2007) Photoageing: Mechanism, Prevention and Therapy. The British Journal of Dermatology, 157, 874-887. http://dx.doi.org/10.1111/j.1365-2133.2007.08108.x

[12] Quan, T., Qin, Z., Robichaud, P., Voorhees, J.J. and Fisher, G.J. (2011) CCN1 Contributes to Skin Connective Tissue Aging by Inducing Age-Associated Secretory Phenotype in Human Skin Dermal Fibroblasts. Journal of Cell Commu- 
nication and Signaling, 5, 201-207. http://dx.doi.org/10.1007/s12079-011-0144-0

[13] Varani, J., Warner, R.L., Gharaee-Kermani, M., et al. (2000) Vitamin A Antagonizes Decreased Cell Growth and Elevated Collagen-Degrading Matrix Metalloproteinases and Stimulates Collagen Accumulation in Naturally Aged Human Skin. The Journal of Investigative Dermatology, 114, 480-486.

http://dx.doi.org/10.1046/j.1523-1747.2000.00902.x

[14] Fisher, G.J., Kang, S., Varani, J., et al. (2002) Mechanisms of Photoaging and Chronological Skin Aging. Archives of Dermatology, 138, 1462-1470. http://dx.doi.org/10.1001/archderm.138.11.1462

[15] Kligman, L.H. (1996) The Hairless Mouse Model for Photoaging. Clinics in Dermatology, 14, 183-195. http://dx.doi.org/10.1016/0738-081X(95)00154-8

[16] Benavides, F., Oberyszyn, T.M., VanBuskirk, A.M., Reeve, V.E. and Kusewitt, D.F. (2009) The Hairless Mouse in Skin Research. Journal of Dermatological Science, 53, 10-18. http://dx.doi.org/10.1016/j.jdermsci.2008.08.012

[17] Inomata, S., Matsunaga, Y., Amano, S., et al. (2003) Possible Involvement of Gelatinases in Basement Membrane Damage and Wrinkle Formation in Chronically Ultraviolet B-Exposed Hairless Mouse. The Journal of Investigative Dermatology, 120, 128-134. http://dx.doi.org/10.1046/j.1523-1747.2003.12021.x

[18] Ropke, C.D., Sawada, T.C., da Silva, V.V., Michalany, N.S. and de Moraes Barros, S.B. (2005) Photoprotective Effect of Pothomorphe umbellata Root Extract against Ultraviolet Radiation Induced Chronic Skin Damage in the Hairless Mouse. Clinical and Experimental Dermatology, 30, 272-276. http://dx.doi.org/10.1111/j.1365-2230.2005.01749.x

[19] Kligman, L.H., Mezick, J.A., Capetola, R.J. and Thorne, E.G. (1992) Lifetime Topical Application of Tretinoin to Hairless Mice. Acta Dermato-Venereologica, 72, 418-422.

[20] Peres, P.S., Terra, V.A., Guarnier, F.A., Cecchini, R. and Cecchini, A.L. (2011) Photoaging and Chronological Aging Profile: Understanding Oxidation of the Skin. Journal of Photochemistry and Photobiology B, Biology, 103, 93-97. http://dx.doi.org/10.1016/j.jphotobiol.2011.01.019

[21] Sakura, M., Chiba, Y., Kamiya, E., et al. (2013) Spontaneous Occurrence of Photoageing-Like Phenotypes in the Dorsal Skin of Old SAMP1 Mice, an Oxidative Stress Model. Experimental Dermatology, 22, 62-64. http://dx.doi.org/10.1111/exd.12059

[22] Hosokawa, M. (2002) A Higher Oxidative Status Accelerates Senescence and Aggravates Age-Dependent Disorders in SAMP Strains of Mice. Mechanisms of Ageing and Development, 123, 1553-1561. http://dx.doi.org/10.1016/S0047-6374(02)00091-X

[23] Chiba, Y., Yamashita, Y., Ueno, M., et al. (2005) Cultured Murine Dermal Fibroblast-Like Cells from SenescenceAccelerated Mice as in Vitro Models for Higher Oxidative Stress Due to Mitochondrial Alterations. Journal of Gerontology: Series A, Biological Sciences \& Medical Sciences, 60, 1087-1098. http://dx.doi.org/10.1093/gerona/60.9.1087

[24] Chiba, Y., Shimada, A. and Hosokawa, M. (2010) The SAM Strain of Mice, a Higher Oxidative Stress, Age-Dependent Degenerative Disease, and Senescence Acceleration Model. In: Bondy, S.C. and Maiese, K., Eds., Aging and Age-Related Disorders, Oxidative Stress in Applied Basic Research and Clinical Practice, Springer Science + Business Media LLC, New York, 359-380.

[25] Schwartz, E., Sapadin, A.N. and Kligman, L.H. (1998) Ultraviolet B Radiation Increases Steady-State mRNA Levels for Cytokines and Integrins in Hairless Mouse Skin: Modulation by Topical Tretinoin. Archives of Dermatological Research, 290, 137-144. http://dx.doi.org/10.1007/s004030050279

[26] Hernandez Cruz, A., Garcia-Jimenez, S., Zucatelli Mendonca, R. and Petricevich, V.L. (2008) Pro- and Anti-Inflammatory Cytokines Release in Mice Injected with Crotalus durissus Terrificus Venom. Mediators of Inflammation, 2008, Article ID: 874962. http://dx.doi.org/10.1155/2008/874962

[27] Nyati, K.K., Prasad, K.N., Rizwan, A., Verma, A. and Paliwal, V.K. (2011) TH1 and TH2 Response to Campylobacter jejuni Antigen in Guillain-Barre Syndrome. Archives of Neurology, 68, 445-452.

http://dx.doi.org/10.1001/archneurol.2011.51

[28] Kidd, P. (2003) Th1/Th2 Balance: The Hypothesis, Its Limitations, and Implications for Health and Disease. Alternative Medicine Review, 8, 223-246.

[29] Asadullah, K., Sterry, W., Stephanek, K., et al. (1998) IL-10 Is a Key Cytokine in Psoriasis. Proof of Principle by IL-10 Therapy: A New Therapeutic Approach. The Journal of Clinical Investigation, 101, 783-794. http://dx.doi.org/10.1172/JCI1476

[30] Kim, Y.K., Jung, H.G., Myint, A.M., Kim, H. and Park, S.H. (2007) Imbalance between Pro-Inflammatory and AntiInflammatory Cytokines in Bipolar Disorder. Journal of Affective Disorders, 104, 91-95. http://dx.doi.org/10.1016/j.jad.2007.02.018 
Scientific Research Publishing (SCIRP) is one of the largest Open Access journal publishers. It is currently publishing more than 200 open access, online, peer-reviewed journals covering a wide range of academic disciplines. SCIRP serves the worldwide academic communities and contributes to the progress and application of science with its publication.

Other selected journals from SCIRP are listed as below. Submit your manuscript to us via either submit@scirp.org or Online Submission Portal.
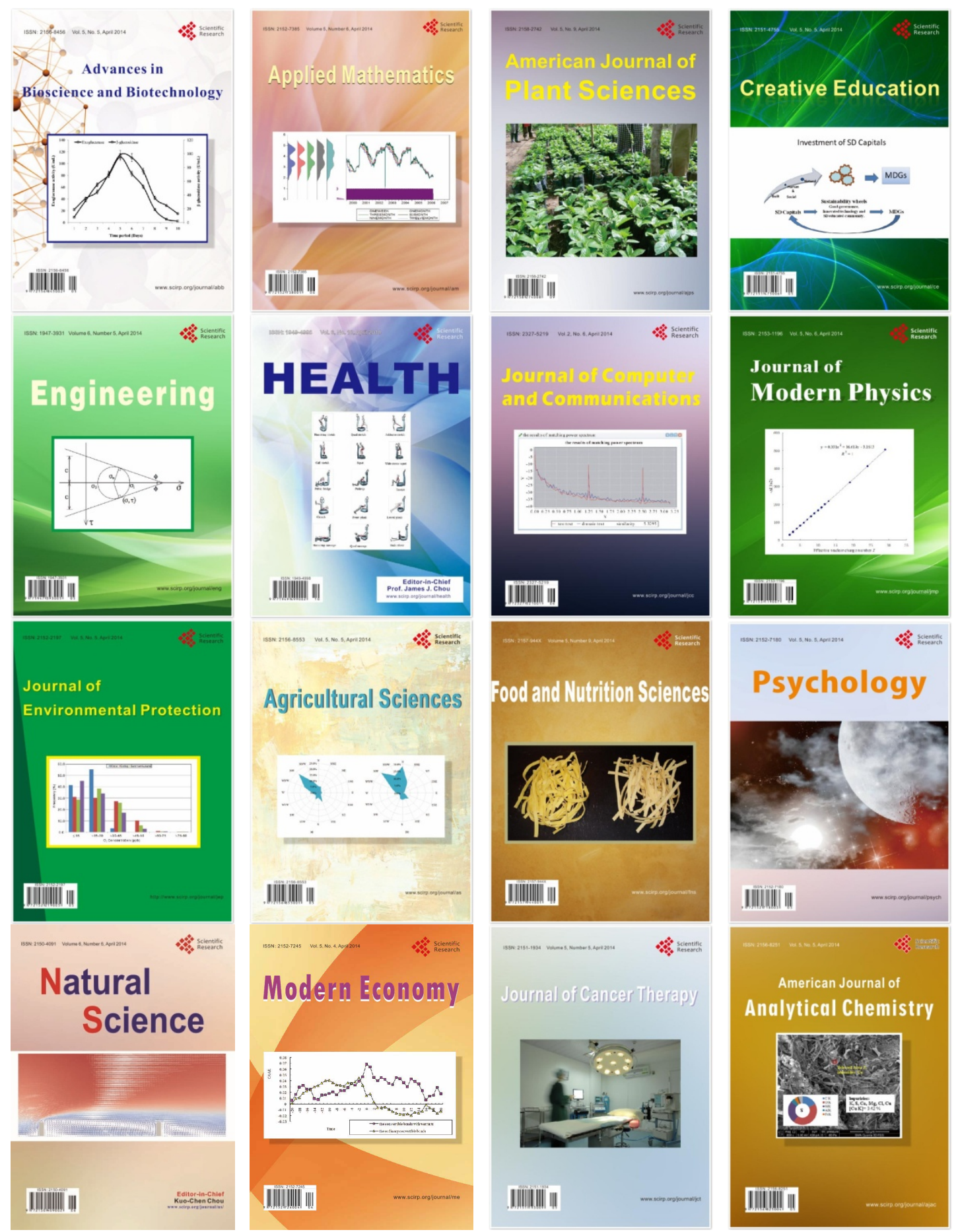